\title{
Stridor in multiple system atrophy
}

\section{Consensus statement on diagnosis, prognosis, and treatment}

Pietro Cortelli, MD, PhD, * Giovanna Calandra-Buonaura, MD, PhD, * Eduardo E. Benarroch, MD, Giulia Giannini, MD, Alex Iranzo, MD, Phillip A. Low, MD, Paolo Martinelli, MD, Federica Provini, MD, PhD, Niall Quinn, MD, Eduardo Tolosa, MD, PhD, Gregor K. Wenning, MD, PhD, Giovanni Abbruzzese, MD, Pamela Bower, Enrico Alfonsi, MD, Imad Ghorayeb, MD, PhD, Tetsutaro Ozawa, MD, PhD, Claudio Pacchetti, MD, Nicolò Gabriele Pozzi, MD, Claudio Vicini, MD, Angelo Antonini, MD, PhD, Kailash P. Bhatia, MD, Jacopo Bonavita, MD, Horacio Kaufmann, MD, Maria Teresa Pellecchia, MD, PhD, Nicole Pizzorni, MSc, Antonio Schindler, MD, François Tison, MD, PhD, Luca Vignatelli, MD, PhD, and Wassilios G. Meissner, MD, PhD

Neurology ${ }^{\circledR}$ 2019;93:630-639. doi:10.1212/WNL.0000000000008208

\begin{abstract}
Multiple system atrophy (MSA) is a neurodegenerative disorder characterized by a combination of autonomic failure, cerebellar ataxia, and parkinsonism. Laryngeal stridor is an additional feature for MSA diagnosis, showing a high diagnostic positive predictive value, and its early occurrence might contribute to shorten survival. A consensus definition of stridor in MSA is lacking, and disagreement persists about its diagnosis, prognosis, and treatment. An International Consensus Conference among experts with methodological support was convened in Bologna in 2017 to define stridor in MSA and to reach consensus statements for the diagnosis, prognosis, and treatment. Stridor was defined as a strained, high-pitched, harsh respiratory sound, mainly inspiratory, occurring only during sleep or during both sleep and wakefulness, and caused by laryngeal dysfunction leading to narrowing of the rima glottidis. According to the consensus, stridor may be recognized clinically by the physician if present at the time of examination, with the help of a witness, or by listening to an audio recording. Laryngoscopy is suggested to exclude mechanical lesions or functional vocal cord abnormalities related to different neurologic conditions. If the suspicion of stridor needs confirmation, drug-induced sleep endoscopy or video polysomnography may be useful. The impact of stridor on survival and quality of life remains uncertain. Continuous positive airway pressure and tracheostomy are both suggested as symptomatic treatment of stridor, but whether they improve survival is uncertain. Several research gaps emerged involving diagnosis, prognosis, and treatment. Unmet needs for research were identified.
\end{abstract}

Correspondence

Prof. Cortelli

pietro.cortelli@unibo.it

\begin{abstract}
*These authors contribute equally to the manuscript.
From the IRCCS (P.C., G.C.-B., G.G., F.P., L.V.), Istituto delle Scienze Neurologiche di Bologna, Bologna, Italy; Dipartimento di Scienze Biomediche e Neuromotorie (P.C., G.C.-B., G.G. P.M., F.P.), Università di Bologna, Bologna, Italy; Department of Neurology (E.E.B., P.A.L.), Mayo Clinic, Rochester, MN; Multidisciplinary Sleep Unit (A.I.), Neurology Service, Hospital Clinic de Barcelona, IDIBAPS CIBERNED, Barcelona, Spain; UCL Queen Square Institute of Neurology (N.Q.), Queen Square, London; Parkinson's Disease and Movement Disorders Unit (E.T.), Neurology Service, Hospital Clinic de Barcelona; Institut d'Investigacions Biomèdiques August Pi i Sunyer (IDIBAPS) (E.T.), University of Barcelona (UB), and Centre for Networked Biomedical Research on Neurodegenerative Diseases (CIBERNED), Barcelona, Spain; Department of Neurology (G.K.W.), Innsbruck Medical University, Innsbruck, Austria; Department of Neuroscience (G.A.), Rehabilitation, Ophthalmology, Genetics and Maternal Child Health, University of Genoa, Genoa, Italy; The Multiple System Atrophy Coalition, Inc. (P.B.), Charlotte, NC; Neurophysiopathology Unit (E.A.), IRCCS “C. Mondino" Foundation, Pavia, Italy; Department of Clinical Neurophysiology (I.G.), CHU de Bordeaux, Bordeaux, France; Université de Bordeaux (I.G.), Institut de Neurosciences Cognitives et Intégratives d'Aquitaine, Bordeaux, France; CNRS (I.G.), Institut de Neurosciences Cognitives et Intégratives d'Aquitaine, Bordeaux, France; Department of Neurology (T.O.), Uonuma Institute of Community Medicine, Niigata University Medical and Dental Hospital, Minami Uonuma, Niigata, Japan; Parkinson's Disease and Movement Disorders Unit (C.P., N.G.P.), IRCCS “C. Mondino" Foundation, Pavia; Dipartimento di Medicina Specialistica (C.V.), Diagnostica e Sperimentale (DIMES), University of Bologna, Bologna, Italy; Dipartimento di Scienze biomediche e chirurgico specialistiche (C.V.), University of Ferrara, Ferrara, Italy; Department of Neurosciences (A.A.), University of Padua, Padua, Italy; Department of Clinical and Motor Neuroscience (A.P.B.), UCL Institute of Neurology, National Hospital for Neurology and Neurosurgery, Queen Square, London; Spinal Unit (..B.), Montecatone Rehabilitation Institute, Imola, Italy; Department of Neurology (H.K.), New York University School of Medicine, New York, NY; Department of Medicine (M.T.P.), Surgery and Dentistry "Scuola Medica Salernitana", University of Salerno, Salerno, Italy; “Luigi Sacco" Department of Biomedical and Clinical Sciences (N.P., A.S.), University of Milan, Milan, Italy; Service de Neurologie (F.T., W.G.M.), CRMR Atrophie Multisystématisée, CHU Bordeaux, Bordeaux, France; Univ. de Bordeaux (F.T., W.G.M.), Institut des Maladies Neurodégénératives, Bordeaux, France; and Department Medicine (W.G.M.), University of Otago, Christchurch, and New Zealand Brain Research Institute, Christchurch, New Zealand.
\end{abstract}

Go to Neurology.org/N for full disclosures. Funding information and disclosures deemed relevant by the authors, if any, are provided at the end of the article.

This is an open access article distributed under the terms of the Creative Commons Attribution-NonCommercial-NoDerivatives License 4.0 (CC BY-NC-ND), which permits downloading and sharing the work provided it is properly cited. The work cannot be changed in any way or used commercially without permission from the journal. 


\section{Glossary}

CPAP = continuous positive airway pressure; DISE = drug-induced sleep endoscopy; IRCCS-ISNB = Istituto di Ricovero e Cura a Carattere Scientifico delle Scienze Neurologiche di Bologna; MSA = multiple system atrophy; MSA-C = MSA-cerebellar; MSA-P = MSA-parkinsonian; VPSG = video polysomnography.

Multiple system atrophy (MSA) is a progressive neurodegenerative disorder characterized by a variable combination of autonomic failure, cerebellar ataxia, and parkinsonian features, typically poorly responsive to levodopa. The diagnostic criteria define 3 degrees of certainty for diagnosis, possible, probable, and definite, and 2 phenotypes, parkinsonian (MSA-P) and cerebellar (MSA-C), according to the predominant feature at the time of evaluation. ${ }^{1,2}$ Causes of death in MSA commonly include bronchopneumonia, urosepsis, or sudden death that often occurs during sleep. ${ }^{2}$

Several sleep-related breathing disorders, including stridor and central and obstructive sleep apneas, frequently occur in $\mathrm{MSA}^{3,4}$ Stridor has been included in the diagnostic criteria as additional feature for the diagnosis of possible MSA, showing a high diagnostic positive predictive value. ${ }^{5-7}$ A recent study has suggested that early stridor onset is an independent risk factor for shorter survival ${ }^{8}$; however, its prognostic role remains controversial. $^{9-11}$ This may be a consequence of the distinct design, population characteristics, and MSA diagnostic certainty (clinical vs autopsy based) across studies. Furthermore, the lack of a universal definition for stridor and a gold standard for its diagnostic assessment may explain result heterogeneity.

Two main options have been suggested for treating stridor: tracheostomy or continuous positive airway pressure (CPAP). ${ }^{5}$ Tracheostomy is currently preferred in the advanced disease stage for severe stridor and in case of stridor during wakefulness with immobile vocal cords on laryngoscopy. ${ }^{5} \mathrm{CPAP}$ as a noninvasive therapy can be used for mild and moderate intensity stridor occurring during sleep and related obstructive apneas. However, guidelines for stridor management are lacking, and only a few studies have assessed the role of stridor treatment on survival. ${ }^{8,12-14}$ The "Istituto di Ricovero e Cura a Carattere Scientifico delle Scienze Neurologiche di Bologna” (IRCCSISNB) promoted an international consensus conference among experts in the field with methodological support, convened in Bologna, Italy, on October 6 and 7, 2017. The aims of the conference were to (1) determine criteria for the diagnosis of stridor and consequently define stridor in MSA, (2) define the prognostic value of stridor on MSA survival, (3) suggest therapeutic options for stridor, and (4) provide statements for future research after systematically reviewing evidence and identifying unmet needs for clinical practice and research gray zones.

\section{Methods}

The method was inspired by the US National Institutes of Health Consensus Development Program ${ }^{15}$ and adapted from the Methodological Handbook of the Italian National Guideline System. ${ }^{16}$ The consensus conference method is recommended for addressing important clinical questions in the face of limited good quality evidence. The main outcome, a consensus statement, represents the collective opinions of an expert panel, derived from systematic review and discussion of available evidence. ${ }^{17}$ The organizer of the Bologna Consensus Conference was the IRCCSISNB, Italy. Planning and execution of the project was performed in 4 phases: (1) assignment, (2) scoping, (3) assessment, and (4) the consensus conference itself. All activities, from conception to realization, were completed between February and October 2017. During the same period, a parallel project on dysphagia in patients with MSA was performed.

In (1) the assignment phase, the entities and their roles were defined, and participants were nominated and invited. Four entities were appointed: (1) the Scientific Committee (6 members) planned and organized the whole project, nominated the Consensus Development Panel and Workgroup members, and chose the questions to be answered by the Workgroup; (2) the Technical Committee (2 members) established methods and rules of the Consensus Conference, assisted with defining questions, and performed the systematic review with evidence mapping; (3) 1 Workgroup of experts ( 8 members) focused on stridor, synthesized and integrated information from the systematic review before the consensus conference, provided shared answers to the proposed questions, and presented their findings during the Consensus Conference, including research gaps and a proposal for future research; and (4) the Consensus Development Panel (8 members) chaired the Consensus Conference, established presentation procedures, and provided final statements.

In (2) the scoping phase, the scope and the protocol for the systematic review (registered on PROSPERO database, PROSPERO 2018 CRD42018079084) $)^{18}$ and the protocol for the conference were defined. The Scientific Committee identified the topics and together with the Technical Committee formulated the questions to be addressed. The questions were framed according to the Problem/Patient/ Population, Intervention/Indicator, Comparison, Outcome model. ${ }^{19}$

In (3) the assessment phase, the Technical Committee performed a systematic review with evidence mapping to assess the state of knowledge on stridor in MSA. The systematic review 
was performed following accepted criteria for the good conduct and reporting of systematic reviews ${ }^{18}$ and reported according to Preferred Reporting Items for Systematic Reviews and MetaAnalyses guidelines. ${ }^{20}$ The descriptive map of available research evidence was performed by adapting the methodology reported by the Global Evidence Mapping Initiative, ${ }^{21}$ which involved detailed coding of included studies and in-depth syntheses of the available research. Studies eligible for inclusion were published studies of any kind of design reporting original data on subjects with MSA having stridor during sleep, dealing with diagnosis, prognosis, and/or treatment. Studies published in abstract form, narrative review, or concept papers were excluded. Published studies were identified from the National Library of Medicine's MEDLINE database, Elsevier's EMBASE database, and the Cochrane Central Register of Controlled Trials by means of specific search strategies, using a combination of exploded $\mathrm{MeSH}$ terms and free text combing the concepts of stridor in sleep and MSA (see protocol on PROSPERO for details). Reference lists of identified articles were reviewed to find additional references. All abstracts or full articles without electronic abstracts were reviewed independently by 2 reviewers to identify potentially relevant studies. Each study was classified according to various descriptors, including topic domain, sample size, design, presence of diagnostic criteria of the stridor, and level of evidence according to the Classification of Evidence Schemes of the Clinical Practice Guideline Process Manual of the American Academy of Neurology (2011). ${ }^{22}$ Briefly, each study was graded according to its risk of bias from Class I (highest quality) to Class IV (lowest quality). Risk of bias was judged by assessing specific quality elements (i.e., study design, patient spectrum, data collection, and masking) for each clinical topic (diagnostic accuracy, prognostic accuracy, and therapeutic). Disagreement between the 2 reviewers was resolved by discussion.

The Technical Committee then sent to the Workgroup experts a detailed summary of the systematic review with evidence mapping, the questions, and the abstracts of the most prominent studies, classified by topic and quality. The workgroup produced draft answers to be discussed during the Consensus Conference.

The Consensus Conference (4) was held over 2 days (October 6 and 7, 2017) in Bologna. On the first day, the Consensus Development Panel established the rules for the open discussion meetings, appraised the state of knowledge on stridor in MSA and the preliminary answers provided by experts, and proposed future strategies for the publication of the consensus statements. During a contemporaneous closed meeting, the experts independently discussed and reached final answers to the questions assigned to them. Finally, an open discussion was held in which experts presented their findings and all participants debated openly to reach consensus regarding each topic and the need for further research. On the second day, the Consensus Development Panel drafted a summary of the findings in a closed session. The chairperson then reported the findings in an open session that included the consensus conference participants and other members of the scientific community and officials from the organizing institution. Finally, experts gave a presentation on needs for future research.

\section{Results}

\section{Systematic review with evidence mapping}

The literature search was performed in July 2017 and retrieved 212 citations after duplicate removal (figure). Each retrieved article was screened to assess potential relevance, and 53 were reviewed from the full text for inclusion. A total of 42 studies finally met the prespecified inclusion criteria, and 34 were used as basis for the statements. The majority of studies on diagnosis and treatment were of Class IV quality; those on prognosis of Class III (tables 1-4). Most studies on diagnosis and treatment included fewer than 10 patients and were case series or case reports as design. The cohort design was used in the majority of prognosis studies.

\section{Diagnosis of stridor}

Stridor is a respiratory disturbance that in MSA typically occurs during sleep and might develop at any time point in the disease process. According to clinical and clinicopathologic studies, stridor prevalence in MSA ranges from $12 \%$ to $42 \%^{8-12,23-25}$ and is similar in MSA-C and MSA-P. ${ }^{8,9,11,12}$ In 2 studies, $4 \%-5.2 \%$ of patients presented stridor as an initial manifestation of MSA. ${ }^{8,26}$

The clinical diagnosis of stridor remains challenging. The presence of a nighttime witness is typically necessary to suspect stridor because patients may be unaware of it. A high-pitched sound or heavy snoring are the symptoms frequently reported in patients who eventually turn out to have stridor, illustrating the problem of the differential diagnosis with snoring and obstructive sleep apnea syndrome, which are 2 other frequent sleep-related breathing disorders in MSA. 3,4,10,24,27-29

The term "peculiar snoring" was initially used to describe the distinctive noise occurring in MSA due to vibration of the vocal folds in inspiration, with a fundamental acoustic frequency of $260-330 \mathrm{~Hz}$, different from that of ordinary soft palate snoring. ${ }^{30}$ Subsequently, only a single study has analyzed the acoustic features of stridor in 22 patients with MSA by means of the Multi-Dimensional Voice Program. ${ }^{31}$ This study showed that stridor can be decomposed into rhythmic and semirhythmic waveforms. In both cases, it comprises formats and harmonics, whose presence suggests an origin in the vocal cords. In contrast, the sound analysis of snoring that was available for 18 of these patients revealed an irregular-shaped sound with no formats and harmonics.

Studies with video polysomnography (VPSG), which include audio recording and concurrent evaluation of vocal cord motion by fiberoptic laryngoscopy, showed that the highpitched sound identified as stridor in patients with MSA was associated with impaired vocal cord abduction, paradoxical adduction, or both during inspiration and expiration, leading 


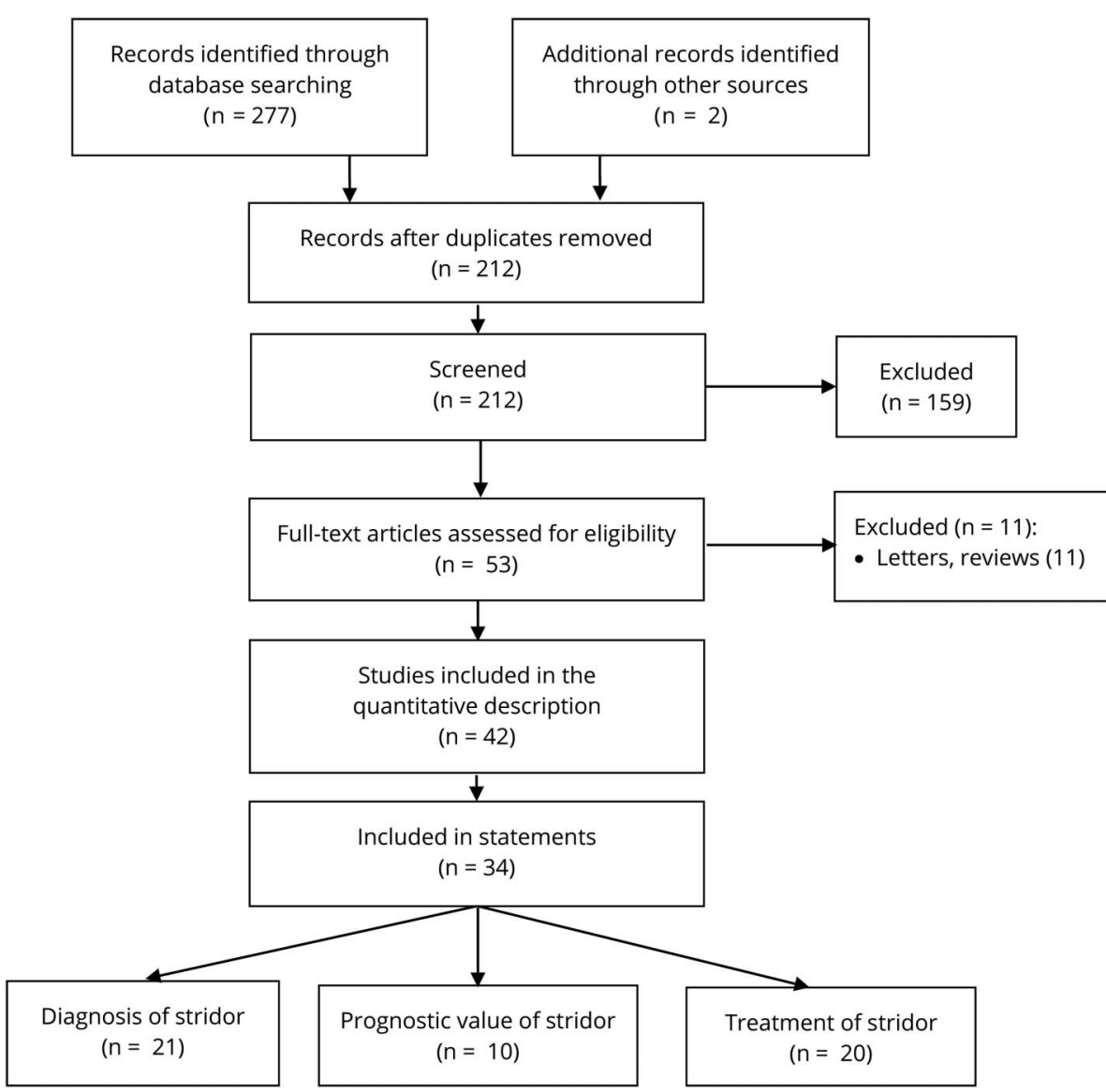

Process and result of the systematic search for studies on stridor in multiple system atrophy. to narrowing of the rima glottidis. This indicates that inspiratory vibration of the narrowed vocal cord folds causes stridor. $^{32-38}$

In 1 VPSG study exploring breathing activity and EMG activity of the respiratory muscles, stridor was accompanied by overactivation of intercostalis and diaphragmatic muscles. In this study, the observation of tonic and subcontinuous muscle recruitment with phasing out of thoracic as opposed to abdominal respiratory traces with paradoxical inward movements of the abdominal wall during inspiration was suggestive of paradoxical breathing. ${ }^{37}$

Further VPSG studies showed that other sleep-related respiratory disturbances such as snoring, central and obstructive sleep apneas, and breathing rate abnormalities (i.e., a pathologic breathing rate increase during non-REM and sleep) may occur in patients with MSA with and without stridor. $^{12,24,33,37-39}$

Laryngoscopy during wakefulness in patients with MSA with stridor, performed to exclude secondary causes or functional vocal cord abnormalities related to other neurologic conditions, can reveal bilateral or unilateral impairment of vocal cord abduction of varying severity or normal vocal cord motility. ${ }^{27,29,32,33,35,36,39-44}$ Conversely, impairment of vocal cord motility during wakefulness was also observed in patients with MSA without stridor during sleep. ${ }^{27}$

Studies with drug-induced sleep endoscopy (DISE) demonstrated impaired abduction or paradoxical adduction of the vocal cords in patients with MSA with stridor who had normal vocal cord motility on awake laryngoscopy. ${ }^{32,33,35-37,41-44}$

Finally, a few studies have performed EMG of laryngeal muscles during wakefulness and drug-induced sleep. Patients with MSA with stridor could present normal EMG activity of adductor and abductor laryngeal muscles during quiet breathing and inspiration. Alternatively, they could show a neurogenic pattern of muscle unit action potential analysis of these muscles associated with tonic activity of adductor muscles during quiet breathing and paradoxical activity during inspiration. During drug-induced sleep, the main patterns were persistent tonic activity or paradoxical activation of laryngeal adductor muscles during inspiration. ${ }^{35-38,44-46}$ 
Table 1 Descriptive features of eligible studies on stridor in MSA

\begin{tabular}{|c|c|c|c|c|c|c|c|c|}
\hline & $\begin{array}{l}\text { All } \\
\text { studies }\end{array}$ & $\begin{array}{l}\text { No. of patients = number } \\
\text { of studies }\end{array}$ & $\begin{array}{l}\text { Cohort } \\
\text { studies }\end{array}$ & $\begin{array}{l}\text { Case-control } \\
\text { studies }\end{array}$ & $\begin{array}{l}\text { Cross-sectional } \\
\text { studies }\end{array}$ & $\begin{array}{l}\text { Case } \\
\text { series }\end{array}$ & $\begin{array}{l}\text { Case } \\
\text { report }\end{array}$ & $\begin{array}{l}\text { Evidence } \\
\text { class }\end{array}$ \\
\hline Topic & $\mathrm{N}$ & $\mathrm{N}$ & $\mathrm{N}$ & $\mathrm{N}$ & $\mathrm{N}$ & $\mathrm{N}$ & $\mathrm{N}$ & \\
\hline \multirow[t]{3}{*}{ Diagnosis } & 24 & $<10$ pts $=14$ studies & - & 2 & 5 & 10 & 7 & $\begin{array}{l}\text { All studies } \\
\text { Class IV }\end{array}$ \\
\hline & & $10-19$ pts $=7$ studies & & & & & & \\
\hline & & $20-50$ pts $=3$ studies & & & & & & \\
\hline \multirow[t]{3}{*}{ Prognosis } & 11 & $<50$ pts $=6$ studies & 10 & - & - & 1 & - & 2 Class II \\
\hline & & $50-99$ pts $=3$ studies & & & & & & 8 Class III \\
\hline & & $>100$ pts $=2$ studies & & & & & & 1 Class IV \\
\hline \multirow[t]{2}{*}{ Treatment } & 25 & $<10$ pts $=12$ studies & 8 & - & - & 10 & 7 & 3 Class III \\
\hline & & $10-19$ pts $=6$ studies & & & & & & 22 Class IV \\
\hline
\end{tabular}

Abbreviation: $\mathrm{MSA}=$ multiple system atrophy; pts = patients.

Each study is graded according to its risk of bias from Class I to Class IV (with I being highest and IV lowest quality).

\section{Statements on the diagnosis of stridor}

Clinical features suggesting the presence of stridor

Statements are based on core literature consisting of Class IV level studies ${ }^{10,12,24,31}$ and expert opinion.

- Stridor is suspected when a high-pitched breathing sound is emitted by the patient during sleep or while awake, or when reported by caregivers.

- Stridor is probably underrecognized because patients and caregivers may be unaware of its presence, especially when it occurs at night.

- Recognition could be possible by the patient or caregiver after imitation of stridor by the physician (see supplementary sound track file, links.lww.com/ WNL/A973).

Home audio recording to support the diagnosis of stridor Statement is based on expert opinion because literature on the use of home audio recording to support the diagnosis of stridor (differential diagnosis of stridor from snoring) is lacking.

- Patients and caregivers should be encouraged to audio record episodes of suspected stridor.

\section{VPSG to support the diagnosis of stridor}

Statements are based on core literature consisting of Class IV level studies ${ }^{10,12,24,31,33,37-39}$ and expert opinion.

- VPSG including audio is not necessary if the physician has already diagnosed stridor.

- VPSG including audio may demonstrate stridor and its inspiratory nature.

- VPSG can characterize other sleep sounds.
Laryngoscopy for assessing stridor

Statements are based on core literature consisting of Class IV level studies ${ }^{27,29,32-37,39-44}$ and expert opinion.

- Laryngoscopy can exclude mechanical lesions (e.g., masses and scars) or functional vocal cord abnormalities related to different neurologic conditions (central or peripheral disorders).

- Laryngoscopy may reveal vocal cord motility impairment in patients with MSA with stridor.

- If awake laryngoscopy is normal, DISE might be considered if the suspicion of sleep-related stridor needs confirmation.

\section{Other investigations for assessing stridor}

Statements are based on core literature consisting of Class IV level studies ${ }^{35-38,44-46}$ and expert opinion.

- There is no evidence that other investigations are useful.

- EMG of the laryngeal muscles may show denervation or abnormal hyperactivity.

Conclusion on diagnostic criteria for stridor and definition of stridor in MSA

- Stridor in MSA is a strained, high-pitched, harsh respiratory sound, mainly inspiratory, caused by laryngeal dysfunction leading to narrowing of the rima glottidis. It may occur only during sleep or it may be present both during sleep and wakefulness.

- Stridor may be recognized clinically if present at the time of neurologic examination, with the help of a witness, or by listening to an audio recording.

- Laryngoscopy is suggested to exclude mechanical lesions (e.g., masses and scars) or functional vocal cord abnormalities related to different neurologic conditions (central or peripheral disorders). 
Table 2 Studies that form the basis of the statements on diagnosis with their level of evidence

\begin{tabular}{|c|c|c|c|c|c|}
\hline $\begin{array}{l}\text { First } \\
\text { author, y }\end{array}$ & Design & No. of patients & Diagnostic test & $\begin{array}{l}\text { Diagnostic } \\
\text { criteria of stridor }\end{array}$ & $\begin{array}{l}\text { Level of } \\
\text { evidence } \\
\text { class }\end{array}$ \\
\hline $\begin{array}{l}\text { Alfonsi, } \\
2016\end{array}$ & $\begin{array}{l}\text { Cross- } \\
\text { sectional }\end{array}$ & $\begin{array}{l}17 \text { (11 with stridor })+40 \\
\text { normal controls }\end{array}$ & EMG; polysomnography & No & IV \\
\hline $\begin{array}{l}\text { Blumin, } \\
2002\end{array}$ & $\begin{array}{l}\text { Case } \\
\text { series }\end{array}$ & 7 & Fiberoptic laryngoscopy & No & IV \\
\hline $\begin{array}{l}\text { Chitose, } \\
2012\end{array}$ & $\begin{array}{l}\text { Case } \\
\text { report }\end{array}$ & 1 & Awake and sleep-induced laryngoscopy & No & IV \\
\hline $\begin{array}{l}\text { Hanson, } \\
1983\end{array}$ & $\begin{array}{l}\text { Cross- } \\
\text { sectional }\end{array}$ & $\begin{array}{l}12 \text { (9 with stridor) + } \\
\text { controls }\end{array}$ & Speech analysis & No & IV \\
\hline $\begin{array}{l}\text { Harcourt, } \\
1996\end{array}$ & $\begin{array}{l}\text { Case } \\
\text { series }\end{array}$ & 18 & Endoscopy; polysomnography & No & IV \\
\hline Iranzo, 2004 & $\begin{array}{l}\text { Cross- } \\
\text { sectional }\end{array}$ & 40 (14 with stridor) & Polysomnography & No & IV \\
\hline Isono, 2001 & $\begin{array}{l}\text { Case } \\
\text { series }\end{array}$ & 10 & EMG under anesthesia and sleep & No & IV \\
\hline $\begin{array}{l}\text { Isozaki, } \\
1996\end{array}$ & $\begin{array}{l}\text { Case- } \\
\text { control }\end{array}$ & 7 & Awake and sleep-induced laryngoscopy & No & IV \\
\hline Koo, 2016 & $\begin{array}{l}\text { Cross- } \\
\text { sectional }\end{array}$ & 22 & Acoustic analysis & Yes & IV \\
\hline Merlo, 2002 & $\begin{array}{l}\text { Case } \\
\text { series }\end{array}$ & 7 & EMG pattern & No & IV \\
\hline $\begin{array}{l}\text { Nonaka, } \\
2006\end{array}$ & $\begin{array}{l}\text { Case } \\
\text { series }\end{array}$ & 5 & Sleep-induced laryngoscopy; EMG & No & IV \\
\hline $\begin{array}{l}\text { Sadaoka, } \\
1996\end{array}$ & $\begin{array}{l}\text { Case- } \\
\text { control }\end{array}$ & 8 & $\begin{array}{l}\text { Polysomnography; esophageal pressure manometry/ } \\
\text { endoscopy }\end{array}$ & Yes & IV \\
\hline $\begin{array}{l}\text { Sadaoka, } \\
1997\end{array}$ & $\begin{array}{l}\text { Case } \\
\text { series }\end{array}$ & 8 & $\begin{array}{l}\text { Acoustic analysis of snoring, polysomnography, } \\
\text { fiberscopic examination under sedation }\end{array}$ & No & IV \\
\hline Shiba, 2006 & $\begin{array}{l}\text { Case } \\
\text { report }\end{array}$ & 1 & EMG & No & IV \\
\hline $\begin{array}{l}\text { Shimohata, } \\
2006\end{array}$ & $\begin{array}{l}\text { Case } \\
\text { report }\end{array}$ & 1 & Polysomnography & No & IV \\
\hline $\begin{array}{l}\text { Shimonata, } \\
2007\end{array}$ & $\begin{array}{l}\text { Case } \\
\text { series }\end{array}$ & 21 (5 with stridor) & $\begin{array}{l}\text { Polysomnography, laryngoscopy during wakefulness } \\
\text { and under anesthesia }\end{array}$ & No & IV \\
\hline Silber, 2000 & $\begin{array}{l}\text { Cross- } \\
\text { sectional }\end{array}$ & 42 (17 with stridor) & Polysomnography & Yes & IV \\
\hline $\begin{array}{l}\text { Stomeo, } \\
2016\end{array}$ & $\begin{array}{l}\text { Case } \\
\text { report }\end{array}$ & 1 & Sleep-induced endoscopy/sound analysis & No & IV \\
\hline $\begin{array}{l}\text { Vetrugno, } \\
2004\end{array}$ & $\begin{array}{l}\text { Cross- } \\
\text { sectional }\end{array}$ & 19 (8 with stridor) & $\begin{array}{l}\text { Polysomnography; intraesophageal pressure } \\
\text { recording in } 3 \text { patients }\end{array}$ & Yes & IV \\
\hline $\begin{array}{l}\text { Vetrugno, } \\
2007\end{array}$ & $\begin{array}{l}\text { Case } \\
\text { series }\end{array}$ & 3 & $\begin{array}{l}\text { Polysomnography including intraesophageal pressure } \\
\text { recording; laryngoscopy; EMG }\end{array}$ & No & IV \\
\hline $\begin{array}{l}\text { Williams, } \\
1979\end{array}$ & $\begin{array}{l}\text { Case } \\
\text { series }\end{array}$ & 12 & Fiberoptic laryngoscopy & No & IV \\
\hline
\end{tabular}

Each study was classified according to various descriptors, including topic domain, sample size, design, presence of diagnostic criteria of the syndrome, and level of evidence according to the Classification of Evidence Schemes of the Clinical Practice Guideline Process Manual of the American Academy of Neurology (2011). Each study was graded according to its risk of bias from Class I to Class IV (with I highest quality and IV lowest quality). Risk of bias was judged by assessing specific quality elements (i.e., study design, patient spectrum, data collection, and masking) for each clinical topic (diagnostic accuracy, prognostic accuracy, and treatment).

- If awake laryngoscopy is normal and the suspicion of sleep-related stridor needs confirmation, the following additional evaluations might be considered: (1) DISE and (2) VPSG to document the inspiratory nature of the sound, the presence of expiratory intercostalis activation, or the presence of associated sleep breathing disorders. 
Table 3 Studies that form the basis of the statements on prognosis with their level of evidence

\begin{tabular}{llll}
\hline First author, $\mathbf{y}$ & Design & No. of patients & Level of evidence \\
\hline Coon, 2015 & Cohort & 685 (176 with stridor) & II \\
\hline Giannini, 2016 & Cohort & 136 (42 with stridor) & III \\
\hline Glasmacher, 2017 & Systematic review & 6 studies & Not available \\
\hline Koo, 2016 & Cohort & 22 & III \\
\hline Krim, 2007 & Cohort & $86(17$ with stridor $)$ & II \\
\hline Lalich, 2014 & Cohort & $38(25$ with stridor $)$ & III \\
\hline Silber, 2000 & Cohort & $42(30$ with follow-up data, 11 with stridor $)$ & III \\
\hline Starhof, 2016 & Cohort & $99(44$ with stridor $)$ & II \\
\hline Tada, 2007 & Cohort & $49(18$ with stridor $)$ & III \\
\hline Yamaguchi, 2003 & Cohort & $83(33$ with stridor $)$ & III \\
\hline
\end{tabular}

Each study was classified according to various descriptors, including topic domain, sample size, design, presence of diagnostic criteria of the syndrome, and level of evidence according to the Classification of Evidence Schemes of the Clinical Practice Guideline Process Manual of the American Academy of Neurology (2011). Each study was graded according to its risk of bias from Class I to Class IV (with I highest quality and IV lowest quality). Risk of bias was judged by assessing specific quality elements (i.e., study design, patient spectrum, data collection, and masking) for each clinical topic (diagnostic accuracy, prognostic accuracy, and treatment).

\section{Prognostic value of stridor}

Retrospective cohort studies have reported conflicting results on the prognostic value of stridor. ${ }^{47}$ Seven studies did not find an association between the presence of stridor during the disease course and shortened survival. ${ }^{8,9,11,14,48-50}$ In most of these studies, stridor was clinically suspected without instrumental confirmation. In contrast, 1 study showed shorter survival in patients with MSA with stridor after VPSG recording, but not from disease onset. ${ }^{10}$ Finally, the largest study with VPSG found that early onset of stridor (within 3 years from motor or autonomic symptom onset) was an independent predictor of shorter survival. ${ }^{8}$ Based on an analysis with the Multi-Dimensional Voice Program, 1 study reported that acoustic features of stridor may affect survival in MSA. ${ }^{31}$

\section{Statements on the prognostic value of stridor Effect of stridor on survival}

Statements regarding the effect of stridor on survival in MSA are based on core literature consisting of Class II/III level studies, ${ }^{8-11,14,31,48-50}$ a systematic review, ${ }^{47}$ and expert opinion.

- Whether stridor affects survival is uncertain.

- Stridor within 3 years of motor or autonomic symptom onset may shorten survival. However, identification of stridor onset may be difficult.

- Whether specific features of stridor affect survival remains to be determined.

- Stridor during wakefulness is widely considered to reflect a more advanced stage of the disease than stridor occurring during sleep.

Effect of stridor on well-being or health-related quality of life Literature on the effect of stridor on well-being or health-related quality of life is lacking. Statements are based on expert opinion.
- Stridor can be distressing for patients and caregivers.

- The impact on health-related quality of life remains to be determined.

\section{Treatment of stridor}

Four retrospective studies reported that the treatment of stridor improves survival. ${ }^{8,12-14}$ Stridor treatment mainly comprised CPAP or tracheostomy. ${ }^{10,27,29,32,33,35,39,51,52}$ In 3 studies $(<15$ patients), CPAP initially eliminated stridor in almost all patients, ${ }^{12,13,51}$ but the long-term symptomatic effect remains unknown.

Three studies reported survival in patients with MSA treated with CPAP. In 1 small study, CPAP had no effect on survival. ${ }^{10}$ In another prospective cohort study, patients with MSA with stridor receiving CPAP $(\mathrm{n}=13)$ had similar median survival compared with a group of patients with MSA without stridor $(n=26) .{ }^{12}$ Sudden death was reported in 2 of 13 patients following CPAP initiation. ${ }^{13}$

Classic tracheostomy is usually the surgical procedure of choice for stridor. This involves the positioning of a fenestrated cannula, maintained closed during the day to allow phonation. ${ }^{53}$ Alternative techniques such as skin-lined tracheostomy have recently been proposed for the treatment of severe stridor in MSA. ${ }^{54}$ Skin-lined tracheostomy offers several advantages, such as a greater opening of the stoma, higher stability over time, less risk of granulation tissue, and reversibility. In addition, it does not require a cannula during the night, and the stoma is easy to plug during the day.

Three studies focused on the role of tracheostomy on survival. In the largest retrospective study ( $\mathrm{n}=42$ with stridor), patients treated with tracheostomy had longer overall disease 
Table 4 Studies that form the basis of the statements on therapy with their level of evidence

\begin{tabular}{|c|c|c|c|c|}
\hline First author, y & Design & No. of patients & Treatment & Level of evidence \\
\hline Blumin, 2002 & Case series & 7 & CPAP: bilevel positive airway pressure; tracheostomy & IV \\
\hline Chitose, 2012 & Case report & 1 & CPAP; laser arytenoidectomy & IV \\
\hline Ghorayeb, 2005 & Case series & 22 (15 with stridor) & CPAP & IV \\
\hline Giannini, 2016 & Cohort & 136 (42 with stridor; 31 treated) & CPAP (19 pts); tracheostomy (12 pts) & III \\
\hline Harcourt, 1996 & Case series & 18 & CPAP (2 pts); tracheostomy (2 pts); arytenoidectomy (3 pts) & IV \\
\hline Iranzo, 2000 & Cohort & 20 (5 with stridor) & CPAP & IV \\
\hline Iranzo, 2004 & Cohort & 14 (with stridor) & CPAP (13 pts) & IV \\
\hline Isono, 2001 & Case series & 10 & CPAP on laryngeal resistance and muscle activity ( 6 pts) & IV \\
\hline Isozaki, 1996 & Case series & 7 & Tracheostomy & IV \\
\hline Jin, 2007 & Case series & 18 & Tracheostomy (7 pts) & IV \\
\hline Kneisley, 1990 & Case report & 1 & Arytenopexy; vocal cord pinning & IV \\
\hline Lalich, 2014 & Cohort & 1 & CPAP & IV \\
\hline Mahmud, 2015 & Case report & 1 & Laser arytenoidectomy and posterior cordotomy & IV \\
\hline Merlo, 2002 & Case series & 7 & Botulinum toxin (4 pts) & IV \\
\hline Sadaoka, 1996 & Case series & 8 & Tracheostomy & IV \\
\hline Silber, 2000 & Cohort & 42 (30 with follow-up data) & CPAP (5 pts); tracheostomy (4 pts) & IV \\
\hline Stomeo, 2016 & Case report & 1 & Subtotal arytenoidectomy & IV \\
\hline Tada, 2007 & Cohort & 18 (with stridor) & Tracheotomy (12 pts) & III \\
\hline Williams, 1979 & Case series & 12 & Tracheostomy (4 pts) & IV \\
\hline Yamaguchi, 2003 & Cohort & 33 (with stridor; 15 treated) & CPAP; tracheostomy; laryngectomy & III \\
\hline
\end{tabular}

Abbreviation: $\mathrm{CPAP}=$ continuous positive airway pressure; pts = patients.

Each study was classified according to various descriptors, including topic domain, sample size, design, presence of diagnostic criteria of the syndrome, and level of evidence according to the Classification of Evidence Schemes of the Clinical Practice Guideline Process Manual of the American Academy of Neurology (2011). Each study was graded according to its risk of bias from Class I to Class IV (with I highest quality and IV lowest quality). Risk of bias was judged by assessing specific quality elements (i.e., study design, patient spectrum, data collection, and masking) for each clinical topic (diagnostic accuracy, prognostic accuracy, and treatment).

duration, longer disease duration after stridor onset, and longer disease duration after treatment compared with those treated with CPAP. ${ }^{8}$ Another study showed that tracheostomy may reduce the risk of death and of sudden death in patients with MSA with stridor. ${ }^{11}$ One study reported that 2 of the 4 patients with tracheostomy died 1 year after the sleep evaluation, whereas the other 2 were alive 1.9 and 7 years later. ${ }^{10}$

Single case reports have described the use of posterior cordotomy and arytenoidectomy, , $8,43,44,55^{2}$ and botulinum toxin relieved dystonic stridor in 3 of 4 patients 1 month after inoculation. ${ }^{45}$

\section{Statements on the treatment of stridor}

Treatment for symptomatic control of stridor

Statements are based on core literature consisting of Class III/ IV level studies ${ }^{8,10-14,27,29,32,33,35,39,49,51,52}$ and expert opinion.

- Ventilation during sleep (CPAP) can be useful in the symptomatic control of stridor.
- Consider ventilation during sleep (CPAP) as a first-line symptomatic therapy.

- Tracheostomy bypasses upper airway obstruction at laryngeal level and relieves distressing stridor. Tracheostomy is effective in the symptomatic control of stridor.

- Persistent and severe stridor may require tracheostomy.

CPAP for improving survival of patients with stridor

Statement is based on core literature consisting of Class III/IV level studies. ${ }^{8,10,12,13}$

- Whether CPAP improves survival in patients with MSA with stridor is uncertain.

Tracheostomy for improving survival of patients with stridor Statement is based on core literature consisting of Class III/IV level studies. ${ }^{8,10,11}$

- Tracheostomy might improve survival in patients with stridor. 
Other treatment options for stridor

Statement is based on core literature consisting of Class IV level studies including case reports. ${ }^{28,43-45,55}$

- There is insufficient evidence for minimally invasive procedures and botulinum toxin injections for the symptomatic treatment of stridor.

\section{Research needs}

The present Consensus Conference represents the first effort to systematically revise the literature and to provide statements on stridor, a specific feature of MSA, that could affect the disease course. However, despite the importance of this topic, the majority of studies available in the literature were of Class III-IV quality, leading also to statements based on expert opinions. Furthermore, several research gaps emerged during the consensus meeting concerning diagnosis, prognosis, and treatment for stridor.

One main challenge is the diagnosis of stridor. Whether the imitation of stridor by the physician during follow-up visits is sufficient to correctly and earlier identify stridor or whether other tools, such as specific questionnaires or a home audio recording, may improve diagnostic accuracy is unknown. This point could be of crucial importance if the negative prognostic role of early stridor onset is confirmed. It has also to be established when the use of VPSG is necessary for the diagnosis of stridor. For these reasons, a questionnaire for detecting stridor should be developed and its diagnostic accuracy be compared with VPSG in a multicenter prospective study. Similarly, the diagnostic accuracy of sound imitation by the physician or home audio recording should be evaluated. A smartphone application could be developed to automatically recognize the stridor sound. Finally, the place of DISE for early stridor detection requires further investigation, and the method to measure the progression of stridor over time should be standardized.

The relationship between stridor and other breathing disorders (i.e., central apneas and breathing rate abnormalities) and their respective contributions to disease prognosis and survival should be determined through a multicenter prospective study. VPSG should be used to determine stridor and breathing disorders in this study. Moreover, further studies could contribute to elucidate the role on survival of specific characteristic obtained from awake laryngoscopy, DISE, laryngeal EMG (denervation/muscle hyperactivity), and acoustic recordings. In addition, the contribution of stridor to patients and caregiver quality of life is unknown.

To guide the physician for the treatment of stridor, randomized controlled trials comparing the efficacy of CPAP and tracheostomy for different degrees of stridor are warranted. Studies using laryngoscopy and/or laryngeal EMG should be conducted to identify specific characteristics that may predict treatment tolerance and response. Moreover, the usefulness of CPAP for severe stridor, as well as technical aspects including titration, patient compliance, and the timing of follow-up need to be determined. Finally, the usefulness of bilevel PAP should be compared with CPAP. Similarly to CPAP, interventional studies should also compare skin-lined vs conventional tracheostomy.

Literature revision and the emergence of several research gaps on diagnosis, prognosis, and treatment for stridor rise the need of prospective multicenter studies on large samples, and with a randomized controlled design concerning its treatment, to provide high level of evidence in the role of stridor in MSA course.

\section{Author contributions}

Scientific Committee: P. Cortelli (Chair), G. CalandraBuonaura, F. Provini, P. Martinelli, A. Iranzo, and P. A. Low. Technical Committee: L. Vignatelli and G. Giannini. Consensus Panel: G. Abbruzzese (Chairperson), P. Bower, P. Cortelli, P. Martinelli, N. Quinn, E. E. Benarroch, E. Tolosa, and G. K. Wenning. Stridor Workgroup: E. Alfonsi, G. CalandraBuonaura, I. Ghorayeb, W. G. Meissner (Speaker), T. Ozawa, C. Pacchetti, N. G. Pozzi, and C. Vicini. Dysphagia Workgroup: A. Antonini, K. Bhatia, J. Bonavita, H. Kaufmann (Speaker), M. T. Pellecchia, N. Pizzorni, A. Schindler, and F. Tison.

\section{Acknowledgment}

The authors thank Maria Camerlingo (Agenzia sanitaria e sociale regionale, Regione Emilia-Romagna) for assisting in the search strategy.

\section{Study funding}

This study was funded by IRCCS, Istituto delle Scienze Neurologiche di Bologna, Bologna, Italy.

\section{Disclosure}

P. Cortelli and G. Calandra-Buonaura report no disclosures relevant to the manuscript. E. Benarroch: Section Editor, Neurology. G. Giannini and A. Iranzo report no disclosures relevant to the manuscript. P. Low: supported by the NIH (P01NS44233, U54NS065736, R01 FD004789, and R01 NS092625) and Mayo Funds. P. Martinelli reports no disclosures relevant to the manuscript. F. Provini has received honoraria for speaking engagements or consulting activities from Sanofi, Bial, Fidia, Vanda Pharmaceuticals, Zambon, Eisai Japan, and Italfarmaco. N. Quinn reports no disclosures relevant to the manuscript. E. Tolosa received honoraria for consultancy from Novartis, Teva, Bial, Accorda, Boehringer Ingelheim, UCB, Solvay, Lundbeck, and Biogen and has received funding for research from Spanish Network for Research on Neurodegenerative Disorders (CIBERNED)-Instituto Carlos III (ISCIII) and The Michael J. Fox Foundation for Parkinson's Research (MJFF). G. Wenning, G. Abbruzzese, P. Bower, E. Alfonsi, I. Ghorayeb, T. Ozawa, C. Pacchetti, N. Pozzi, C. Vicini, A. Antonini, K. Bhatia, J. Bonavita, H. Kaufmann, M. Pellecchia, N. Pizzorni, A. Schindler, F. Tison, L. Vignatelli, and W. Meissner report no disclosures. Outside the present work, W. Meissner has received fees for editorial activities with Springer, for consultancy activities from Affiris, Biohaven, Lundbeck, and 
Sanofi, teaching honoraria from UCB and MDS, and research support from the Michael J Fox Foundation, the University Hospital Bordeaux, the French Health Ministry, the European Community, ANR, ARAMISE, PSP France, MSA Coalition, ARAMISE, and LABEX Excellence Initiative. Go to Neurology.org/N for full disclosures.

\section{Publication history}

Received by Neurology March 22, 2019. Accepted in final form June 20, 2019.

\section{References}

1. Gilman S, Wenning GK, Low PA, et al. Second consensus statement on the diagnosis of multiple system atrophy. Neurology 2008;71:670-676.

2. Fanciulli A, Wenning GK. Multiple-system atrophy. N Engl J Med 2015;372: $249-263$.

3. Abbott SM, Videnovic A. Sleep disorders in atypical parkinsonism. Mov Disord Clin Pract 2014;1:89-96.

4. Iranzo A. Sleep and breathing in multiple system atrophy. Curr Treat Options Neurol 2007;9:347-353

5. Ozawa T, Sekiya K, Aizawa N, Terajima K, Nishizawa M. Laryngeal stridor in multiple system atrophy: clinicopathological features and causal hypotheses. J Neurol Sci 2016; 361:243-249.

6. Osaki Y, Ben-Shlomo Y, Lees AJ, Wenning GK, Quinn NP. A validation exercise on the new consensus criteria for multiple system atrophy. Mov Disord 2009;24: 2272-2276.

7. Köllensperger M, Geser F, Seppi K, et al. Red flags for multiple system atrophy. Mov Disord 2008;23:1093-1099.

8. Giannini G, Calandra-Buonaura G, Mastrolilli F, et al. Early stridor onset and stridor treatment predict survival in 136 patients with MSA. Neurology 2016;87: 1375-1383.

9. Coon EA, Sletten DM, Suarez MD, et al. Clinical features and autonomic testing predict survival in multiple system atrophy. Brain 2015;138:3623-3631.

10. Silber MH, Levine S. Stridor and death in multiple system atrophy. Mov Disord 2000; 15:699-704.

11. Tada M, Onodera O, Tada M, et al. Early development of autonomic dysfunction may predict poor prognosis in patients with multiple system atrophy. Arch Neurol 2007; 64:256-260.

12. Iranzo A, Santamaria J, Tolosa E, et al. Long-term effect of CPAP in the treatment of nocturnal stridor in multiple system atrophy. Neurology 2004;63:930-932.

13. Ghorayeb I, Yekhlef F, Bioulac B, Tison F. Continuous positive airway pressure for sleep-related breathing disorders in multiple system atrophy: long-term acceptance. Sleep Med 2005;6:359-362.

14. Yamaguchi M, Arai K, Asahina M, Hattori T. Laryngeal stridor in multiple system atrophy. Eur Neurol 2003;49:154-159.

15. Nair R, Aggarwal R, Khanna D. Methods of formal consensus in classification/ diagnostic criteria and guideline development. Semin Arthritis Rheum 2011;41: 95-105.

16. Candiani G, Colombo C, Daghini R, et al. Manuale metodologico: come organizzare una conferenza di consenso. Istituto Superiore di Sanità, Sistema Nazionale Linee Guida SNLG, Roma, Novembre 2009 [online]. Available at: medicinanarrativa.eu/ wp-content/uploads/consensus_conference-1.pdf. Accessed September 29, 2018.

17. American College of Chest Physicians. Consensus Statement Methodology [online] Available at: chestnet.org/Guidelines-and-Resources/About-CHEST-Guidelines Guideline-Development. Accessed February 28, 2019.

18. Centre for Reviews and Dissemination. Systematic Reviews: CRD's guidance for undertaking systematic reviews in health care. 2009. Available at: york.ac.uk/crd/ guidance/. Accessed February 28, 2019.

19. CEBM- Centre for Evidence-Based Medicine, PICO Structure. Available at: cebm. net/2014/06/asking-focused-questions/. Accessed February 28, 2019.

20. Moher D, Liberati A, Tetzlaff J, Altman DG, Group P. Preferred reporting items for systematic reviews and meta-analyses: the PRISMA statement. BMJ 2009;339:b2535.

21. Bragge P, Clavisi O, Turner T, Tavender E, Collie A, Gruen RL. The Global Evidence Mapping Initiative: scoping research in broad topic areas. BMC Med Res Methodol 2011;11:92.

22. AAN (American Academy of Neurology). Clinical Practice Guideline Process Manual, 2011. St. Paul: The American Academy of Neurology; 2011. Available at tools.aan. com/globals/axon/assets/9023.pdf. Accessed September 29, 2018.

23. Wenning GK, Ben Shlomo Y, Magalhães M, Daniel SE, Quinn NP. Clinical features and natural history of multiple system atrophy. An analysis of 100 cases. Brain 1994; 117 (pt 4):835-845.

24. Vetrugno R, Provini F, Cortelli P, et al. Sleep disorders in multiple system atrophy: a correlative video-polysomnographic study. Sleep Med 2004;5:21-30.

25. Figueroa JJ, Singer W, Parsaik A, et al. Multiple system atrophy: prognostic indicators of survival. Mov Disord 2014;29:1151-1157.
26. Uzawa A, Sakakibara R, Tamura N, et al. Laryngeal abductor paralysis can be a solitary manifestation of multiple system atrophy. J Neurol Neurosurg Psychiatry 2005;76: 1739-1741

27. Williams A, Hanson D, Calne DB. Vocal cord paralysis in the Shy-Drager syndrome. J Neurol Neurosurg Psychiatry 1979;42:151-153.

28. Kneisley LW, Rederich GJ. Nocturnal stridor in olivopontocerebellar atrophy. Sleep 1990;13:362-368.

29. Blumin JH, Berke GS. Bilateral vocal fold paresis and multiple system atrophy. Arch Otolaryngol Head Neck Surg 2002;128:1404-1407.

30. Kakitsuba N, Sadaoka T, Kanai R, Fujiwara Y, Takahashi H. Peculiar snoring in patients with multiple system atrophy: its sound source, acoustic characteristics, and diagnostic significance. Ann Otol Rhinol Laryngol 1997;106:380-384.

31. Koo DL, Lee JY, Joo EY, Hong SB, Nam H. Acoustic characteristics of stridor in multiple system atrophy. PLoS One 2016;11:e0153935.

32. Isozaki E, Naito A, Horiguchi S, Kawamura R, Hayashida T, Tanabe H. Early diagnosis and stage classification of vocal cord abductor paralysis in patients with multiple system atrophy. J Neurol Neurosurg Psychiatry 1996;60:399-402.

33. Sadaoka T, Kakitsuba N, Fujiwara Y, Kanai R, Takahashi H. Sleep-related breathing disorders in patients with multiple system atrophy and vocal fold palsy. Sleep 1996;19: 479-484.

34. Sadaoka T, Kakitsuba N, Fujiwara Y, Kanai R, Takahashi H. Limitation of vocal fold abduction only during sleep in a patient with Shy-Drager syndrome. Am J Otolaryngol 1997; 18:145-147.

35. Isono S, Shiba K, Yamaguchi M, et al. Pathogenesis of laryngeal narrowing in patients with multiple system atrophy. J Physiol (Lond) 2001;536:237-249.

36. Nonaka M, Imai T, Shintani T, Kawamata M, Chiba S, Matsumoto H. Non-invasive positive pressure ventilation for laryngeal contraction disorder during sleep in multiple system atrophy. J Neurol Sci 2006;247:53-58.

37. Vetrugno R, Liguori R, Cortelli $\mathrm{P}$, et al. Sleep-related stridor due to dystonic vocal cord motion and neurogenic tachypnea/tachycardia in multiple system atrophy. Mov Disord 2007;22:673-678.

38. Alfonsi E, Terzaghi M, Cosentino G, et al. Specific patterns of laryngeal electromyography during wakefulness are associated to sleep disordered breathing and nocturnal stridor in multiple system atrophy. Parkinsonism Relat Disord 2016;31: 104-109.

39. Harcourt J, Spraggs P, Mathias C, Brookes G. Sleep-related breathing disorders in the Shy-Drager syndrome. Observations on investigation and management. Eur J Neurol 1996;3:186-190.

40. Hanson DG, Ludlow CL, Bassich CJ. Vocal fold paresis in Shy-Drager syndrome. Ann Otol Rhinol Laryngol 1983;92:85-90.

41. Shimohata $\mathrm{T}$, Nakayama $\mathrm{H}$, Shinoda $\mathrm{H}$, et al. Multiple system atrophy with progressive nocturnal hypoxemia: case report with polysomnography and continuous positive airway pressure treatment. Eur Neurol 2006;56:258-260.

42. Shimohata T, Shinoda H, Nakayama H, et al. Daytime hypoxemia, sleep-disordered breathing, and laryngopharyngeal findings in multiple system atrophy. Arch Neurol 2007;64:856-861.

43. Chitose S, Kikuchi A, Ikezono K, Umeno H, Nakashima T. Effect of laser arytenoidectomy on respiratory stridor caused by multiple system atrophy. J Clin Sleep Med 2012;8:713-715.

44. Stomeo F, Rispoli V, Sensi M, Pastore A, Malagutti N, Pelucchi S. Subtotal arytenoidectomy for the treatment of laryngeal stridor in multiple system atrophy: phonatory and swallowing results. Braz J Otorhinolaryngol 2016;82:116-120.

45. Merlo IM, Occhini A, Pacchetti C, Alfonsi E. Not paralysis, but dystonia causes stridor in multiple system atrophy. Neurology 2002;58:649-652.

46. Shiba K, Isono S. Tracheostomy abolishes paradoxical activation of the vocal cord adductor in multiple system atrophy. Auris Nasus Larynx 2006;33:295-298.

47. Glasmacher SA, Leigh PN, Saha RA. Predictors of survival in progressive supranuclear palsy and multiple system atrophy: a systematic review and meta-analysis. J Neurol Neurosurg Psychiatry 2017;88:402-411.

48. Krim E, Yekhlef F, Chrysostome V, Ghorayeb I, Tison F. Multiple system atrophy: prognostic factors in the "MSA- Aquitaine" cohort. Rev Neurol 2007;163. $54-65$

49. Lalich IJ, Ekbom DC, Starkman SJ, Orbelo DM, Morgenthaler TI. Vocal fold motion impairment in multiple system atrophy. Laryngoscope 2014;124:730-735.

50. Starhof C, Korbo L, Funch Lassen C, Winge K, Friis S. Clinical features in a Danish population-based cohort of probable Multiple System Atrophy patients. Neuroepidemiology 2016;46:261-267.

51. Iranzo A, Santamaria J, Tolosa E. Continuous positive air pressure eliminates nocturnal stridor in multiple system atrophy. Barcelona Multiple System Atrophy Study Group. Lancet 2000;356:1329-1930.

52. Jin K, Onodera H, Chida K, Abe N, Itoyama Y. Spade-shaped vocal cord in a multiple system atrophy patient with nocturnal stridor. Intern Med 2007;46:921.

53. Kuhlo W, Doll E, Franck MC. Successful management of Pickwickian syndrome using long-term tracheostomy [in German]. Dtsch Med Wochenschr 1969;94:1286-1290.

54. Campanini A, De Vito A, Frassineti S, Vicini C. Role of skin-lined tracheotomy in obstructive sleep apnoea syndrome: personal experience. Acta Otorhinolaryngol Ital 2004;24:68-74.

55. Mahmud A, Strens LH, Tedla M. Laser arytenoidectomy and posterior cordotomy in a patient with bilateral vocal cord paralysis due to multiple system atrophy. BMJ Case Rep 2015;2015:1-3. 


\section{Neurology}

\section{Stridor in multiple system atrophy: Consensus statement on diagnosis, prognosis, and treatment}

Pietro Cortelli, Giovanna Calandra-Buonaura, Eduardo E. Benarroch, et al. Neurology 2019;93;630-639

DOI 10.1212/WNL.0000000000008208

This information is current as of September 30, 2019

Updated Information \& Services

References

Subspecialty Collections

Permissions \& Licensing

Reprints including high resolution figures, can be found at: http://n.neurology.org/content/93/14/630.full

This article cites 50 articles, 9 of which you can access for free at: http://n.neurology.org/content/93/14/630.full\#ref-list-1

This article, along with others on similar topics, appears in the following collection(s):

Multiple system atrophy

http://n.neurology.org/cgi/collection/multiple_system_atrophy Prognosis

http://n.neurology.org/cgi/collection/prognosis

Information about reproducing this article in parts (figures,tables) or in its entirety can be found online at:

http://www.neurology.org/about/about_the_journal\#permissions

Information about ordering reprints can be found online:

http://n.neurology.org/subscribers/advertise

Neurology ${ }^{\circledR}$ is the official journal of the American Academy of Neurology. Published continuously since 1951, it is now a weekly with 48 issues per year. Copyright Copyright ( 2019 The Author(s). Published by Wolters Kluwer Health, Inc. on behalf of the American Academy of Neurology.. All rights reserved. Print ISSN: 0028-3878. Online ISSN: 1526-632X.

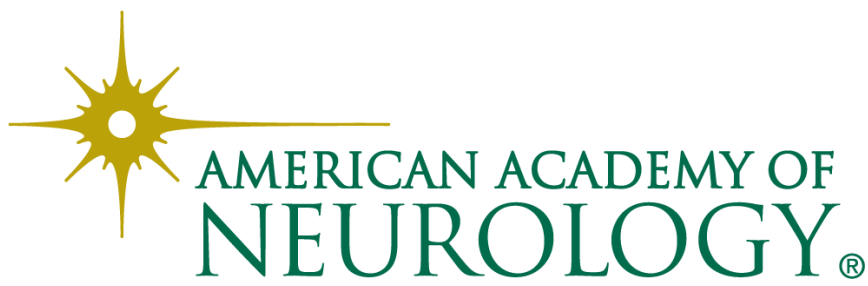

